\title{
The reform of social work practice education and training and supporting practice educators
}

\author{
Jackie Plenty ${ }^{1}$ and David Gower ${ }^{2}$
}

\begin{abstract}
The BA (Hons) Social Work Programme at University Campus Suffolk (UCS) has just completed a full academic year embedding the new Professional Capabilities Framework (PCF) produced by The College of Social Work (TCSW, 2012) and the Standards of Proficiency for Social Work (SoPS) (Health and Care Professionals Council, HCPC, 2012). UCS fully began this process a year ahead of the mandatory requirement for all Higher Education Institutions (HEIs) to introduce these in time for the 2013 -2014 academic year. The new regulatory frameworks were incorporated into the programme to allow an evaluative implementation pilot year and an opportunity for review. This study will set the scene for the important role that practice educators play in social work training and education within the context of recent developments. Despite the disruption created by revision to the teaching and learning on the programme, practice placements and additional training and support required for the social work academics feedback from practice educators and students suggests that the transition was a success. It will also highlight the benefits of the new frameworks in relation to the training and support that was provided, the need for the on-going training and support for practice educators as well as considering lessons to be learned and revisions needed for the next academic year.
\end{abstract}

Keywords: practice education; training, support; evaluation; capabilities; standards.

1. Senior Lecturer in Social Work/Placement Initiative Coordinator

2. Senior Lecturer in Social Work/Placements Organiser

Address for correspondence: University Campus Suffolk, School of Applied Social Science, Social Policy and Social Work Division, University Campus Suffolk, Waterfront Building, Neptune Quay, Ipswich IP4 1QJ. j.plenty@ucs.ac.uk

Date of first (online) publication:

48 J. of Practice Teaching \& Learning 12(2), pp.48-66. DOI: 10.1921/5702120201. @ w\&bb 2013 
Reform of social work practice education and training and supporting practice educators

\section{Introduction}

There is absolutely no doubt that practice educators have been, and remain, an integral part of all social work training programmes; it is fair to say that without them it would not be possible to train social work students sufficiently to manage the demanding and complex work that surrounds the social work profession. Practice, teaching and learning on qualifying social work degree programmes is fundamental to develop social work students into qualifying practitioners. The work based learning provided through placement experiences also allows students to extend their knowledge, skill and value base through the realities of practice, inviting them to improve their performance and be assessed 'on the job'. Students need to be able to transfer academic teaching and learning into the practice arena and, equally to bring their practice alive through informal and formal discussion, reflection and debate alongside assessment processes that make the role of the practice educator vital to the student's success.

Thompson et al. (1994, p.4) remind us that the practice educator role is complex. It incorporates the skills of enabling, supporting, teaching, managing, challenging and evaluating and requires commitment, selfawareness, enthusiasm and creativity. This role is often carried out in tandem with excessive work pressures, frequent changes in national and local law, policy and practice as well as managerialist cultures that can create feelings of anxiety, helplessness and being out of control. Coupled with the frequent re-organisation and re-structuring of social work teams in response to government reforms and budget cuts it is not uncommon for practice educators to feel overwhelmed and unable to continue their role in line with inadequate workload relief and mounting responsibilities (William \& Rutter, 2010, p.130). Equally practice educators can feel pressured into undertaking the moral obligation of training the new workforce in the face of limited financial incentives and a lack of support.

Despite the continuing need to recruit practice educators, it is not always heralded as a key area for staff development. The role of practice education is surely essential for ensuring sufficient training and the assignment of newly qualified social workers. Lindsay and Walton's (2000) study of workforce planning and the strategic development of practice educators highlighted that only a quarter of agencies included practice education as an option during staff development appraisals. There were also significant variations in relation to funding practice educator training.

Linked to this it is not uncommon for experienced practice educators to

49 J. of Practice Teaching \& Learning 12(2), pp.48-66. DOI: 10.1921/5702120201. @ w\&b 2013 
be prevented from continuing their role or having to have a break from it as a result of the re-organisation of teams and departments and changing roles and responsibilities. Factors such as the migration of practice educators across the sector, promotion to management levels and those leaving the profession, taking retirement or whose skills may need updating all impact on the supply and retention of practice educators (Lindsay \& Walton, 2000).

We also need to recognise that practice education can be an incredibly isolating role. It is quite common for a single practice educator to be supporting a student in a social work team or other setting, likewise for an independent practice educator in an off-site role to be visiting the student in the placement than for groups of practice educators and students to be working together. This becomes ever more complex when implementing changes to practice placements, amending portfolio requirements in line with social work reform and managing the changing role and development within social work organisations. The opportunity exists therefore for providing guidance, support and opportunities for practice educators to share new and best practice and undertake training together. Valuing, encouraging and appreciating the demanding role of practice educators in the face of limited placements and a lack of qualified practice educators should also be a real priority for HEIs and partner agencies if the social work profession is to continue to develop and ultimately exist as we desire - to support and enable positive change in ourselves and others.

\section{Context}

Historically, social work practice, education and training have always been exposed to regular revision, development and review mirroring the complexity of social work practice in an ever-changing society. The development of the Practice Educator role has evolved to accommodate and reflect the increasing demands placed on social work students in the face of the dynamic and inconstant socio-economic-political arena. In response to this the practice educator role has moved from being in a position of just needing to be a qualified social work practitioner competent and knowledgeable in the their own field of practice and therefore capable of supervising a social work student, to one that began to be regulated through competency based requirements (CCETSW, 1991).

This was supported with the development of the Practice Teaching Award

50 J. of Practice Teaching \& Learning 12(2), pp.48-66. DOI: 10.1921/5702120201. @ wEbb 2013 
prescribed through the National Post-Qualifying Education and Training Award in Social Work (CCETSW, 1989; GSCC, 2005), 'Providing a 'means of ensuring the quality and standards for students on placement' (Walker et al, 2008, p.3). At the same time we have seen social work training and education move from a two year diploma to a three year degree following substantial reforms by the Department of Health (DoH, 2002). In recent years we have also had to embrace the General Social Care Council that was set up with the responsibility for registering qualified and student social workers that has now been taken over by the Health and Care Professions Council. Alongside this we have had the emergence of the College of Social Work commissioned by the Social Work Task Force in 2009 to provide a centre of excellence for social work. The College operates alongside Skills for Care supporting the Social Work Reform Board (2010) that works in partnership with the Department of Education having key responsibility for the Assessed and Supported Year in Employment (ASYE) (Skills for Care, 2012) and supporting employers to meet their workforce needs.

With the introduction of the TCSW and HCPC radical changes have been presented to further progress the Social Work Reform Board recommendations (2010). The Practice Educator Framework has been replaced with the Practice Educator Professional Standards for Social Work (PEPS) that set out requirements in two stages, commensurate with the different levels of complexity and responsibility in teaching, assessing and supervising social work degree students. The learning outcomes that need to be achieved are set out across four domains (A, B, C and D) for to stage 1 practice educators who can supervise, teach and assess social work degree students in first stage placements. They may also contribute to final stage placements but may not act as the Practice Educator on a day to day basis or take responsibility for final assessment unlike stage 2 practice educators who can take on this role and advance to a mentoring practice educator (TCSW, 2012). All Practice Educators will also need to be registered with the HCPC by 2015. As well as the changes noted above, Year 2 social work students in first placements, will now complete 70 days instead of 100 days, with the remaining 30 days being utilised as skills development days within social work training programmes. Year 3 final placement social work students will still be required to complete a 100 days in a social work placement setting.

All Higher Education Institutes (HEIs) will need to have embedded the PEPS, PCF and SoPS into their training programmes prior to the start of the 2013 - 2014 academic year. To prepare practice educators, students

51 J. of Practice Teaching \& Learning 12(2), pp.48-66. DOI: 10.1921/5702120201. @ w\&b 2013 
and academics for the changes taking place, local partner agencies and HEIs have been required to meet to set out protocols for registering, monitoring and supporting practice educators, ensuring that practice placement portfolio requirements reflect the new frameworks and that teaching and learning is streamlined with the Assessed and Supported Year in Employment (ASYE) (Skills for Care, 2012) that newly qualified social workers are required to undertake during their first year in qualified practice. Ultimately the PCF and SoPS take students on a journey during their first year on a social work training programme and continue through to qualifying and post qualifying experience as part of their Continued Professional Development (TCSW, 2012).

The staged approach of the PCF assesses students in Year 1 in terms of readiness for practice prior to Year 2 and Year 3 where their capabilities are assessed at the end of the first placement and end of the final placement, leading on to the ASYE (Skills for Care, 2012). Social Work has therefore moved from a regulatory system based on competency measures to one of capability measures. McNay et al. (2009, p.73) points out that under the previous framework, it was not competence that was the issue but the competence framework. This was supported with O'Hagan's (1996, p.14) overview of other authors' criticisms that explained that 'in order to achieve competence students were too focused on finding work that would provide evidence rather than taking a holistic approach that mirrors the dynamic complexity of social work'. The development of professional capability is not, however, a new concept. To give examples, the process of broader learning featured in the QAA Benchmark Statement for Social Policy and Social Work (QAA, 2000) put an emphasis on integrated learning which was also captured by Barnett and Coate (2005). In essence whilst competency revolves around a set of guidelines that can measure ability and skills, capability ensures the measurement of skill through actual practice over a period of time set against specific tasks, goals and objectives.

Durkin and Shergill (2000, p.171) also stated that practice competence is concerned with what people can do, rather than what they know and so if competence is concerned with 'doing' then it must be related to a context or subject, allowing the practice educator to evaluate the students' performance fully. Indeed the PCF is set up under nine domains that require the practice educator and student to holistically assess the student's performance, a move away from the tick box approach of the previous National Occupation Standards (Topps England, 2002). One could argue that practice educators have always been required to assess students

52 J. of Practice Teaching \& Learning 12(2), pp.48-66. DOI: 10.1921/5702120201. @ w\&bb 2013 
holistically although this has been based largely on the evidence that is gathered by the students, as presented to the practice educator and through a portfolio of evidence. Practice educators under the new framework are being encouraged to take more responsibility and ownership around gathering evidence themselves through observation and supervision of the student, presenting this information through their placement reports alongside evidence that is presented by the student through the portfolio. This was highlighted in a recent online debate hosted by The College of Social Work around support for students where Novell (2013, p.1) stated that 'giving more scope to the judgement of the practice educator about a student's practice, enabled clearer identification by the practice educator of the areas that students need to work on to demonstrate their practice'. This will require practice educators to be empowered and supported in making overarching judgements around the quality of practice, which makes future practice educator training a vital component in achieving this outcome.

As noted previously the traditional route to a practice educator qualification came through the Practice Teacher Award and the PostQualifying frameworks. Under the new system although the PEPS specify learning outcomes and includes guidance on minimum requirements in terms of mentoring and assessing practice educators, HEIs and partner agencies are being left to develop their own training pathways. Whilst local agendas are important, there is risk of postcode variations or purely tailored local responses at the expense of a consistent national standard. Prior to the implementation of the PEPS, 15 partnerships of employers and HEIs were invited to deliver pilot practice educator programmes under the draft practice educator framework (Skills for Care, 2009). Keen et al. (2010) conducted an evaluation of the pilot training programmes sharing some concerns around the quality of mentors but concluded that it was a positive evaluation indicating the potential effectiveness of the draft practice educator framework. With the PEPS now in full swing, it will require HEIs to ensure that future training programmes meet workforce development needs. The field is therefore wide open in terms of tailoring local training programmes and flexible pathways for practice educators and mentors within partnership consortia.

What has not been mentioned and is lacking in relation to research is the on-going training and support that practice educators require post qualification and during the supervision and assessment of social work students. Although this should be seen as an essential requirement and to some degree all HEIs and partner agencies provide a level of on-going

53 J. of Practice Teaching \& Learning 12(2), pp.48-66. DOI: 10.1921/5702120201. @ w\&b 2013 
training and development, this can be variable. It has now become a vital component of future professional development as noted in Domain D of the PEPS that requests 'effective continuing performance as a practice educator'. Williams and Rutter (2010: 127 - 131) rightly state that 'before we can enable others we need to enable ourselves'. This requires practice educators to understand themselves critically as learners, undertake personal learning and development that includes self-directed learning and keeping up to date with the world of practice education. It is essential therefore that practice educators remain aware of learning and training development within their own organisations as well as other learning providers. This is particularly important for independent practice educators who may no longer be linked to an employer agency. HEIs have an important role to play here in terms of providing good quality practice educator training and support including accessibility to materials and resources that consider the connections between academic teaching and learning and placement experience. (Preston-Shoot et al., 2013).

\section{Implementing the new frameworks}

The social work team at University Campus Suffolk made the decision to implement the new frameworks into the BA (Hons) Social Work programme during the academic year 2012-2013 and have now completed the year-long cycle. This was a year ahead of the mandatory date for implementation. This decision was taken for three reasons; firstly it would allow final year students to become familiar with the new frameworks prior to commencing their Assessed and Supported Year in Employment on completion of the programme. Secondly it allowed us to introduce Year 1 students to the new frameworks at the same time as undertaking the 30 skills development days that would assess their readiness for practice, prior to starting year two. Thirdly it has allowed the university to run a pilot year supported with a full evaluation.

Work began on integrating the new frameworks into the teaching and learning and portfolio requirements on the BA (Hons) Social Work at UCS during the spring of 2012, which included meetings with partner agencies, service users, students and academic staff, with the bulk of the changes being made to the programme across the summer prior to implementation at the beginning of the academic year 2012 -2013. During the early weeks of

54 J. of Practice Teaching \& Learning 12(2), pp.48-66. DOI: 10.1921/5702120201. @ w\&b 2013 
the start of the new semester, academic staff, practice educators and students were briefed and given guidance on the changes that had taken place, with a continued support network built in that involved personal tutors monitoring and guiding students and practice educators during placement meetings and the placement initiative coordinator overseeing the process and guiding the tutors and practice educators through the developments.

The portfolio requirements were culled down and focused on including tasks that would allow students to evidence the wide range of capabilities and standards at the same time as ensuring students would further develop their integration of law and policy, theory to practice and critical thinking underpinned with anti-oppressive and anti-discriminatory practice. Whilst students were undertaking their practice placement, they attended weekly workshops with personal tutors or whole group lectures focused on the integration of academic teaching and learning with work based learning. This juxtaposition of theory and practice has been an on-going feature of the UCS programme for some years and lent itself well to supporting the management of these changes.

All the pieces of work required for the portfolio have prescribed templates with headings that students use to complete the tasks and each piece of work allows students to develop their knowledge, skill and value base in key areas whilst mapping to the new frameworks. Examples include a Tuning-in Summary which encourages students to develop empathy and to explore the emotions and feelings of service users as well as these within themselves. The Critical Case Study Analysis takes students a step further allowing them to take a structured approach to reflection and critical analysis, to consider assessment and intervention strategies, theory to practice alongside examining anti-oppressive practice and value issues (Green Lister and Crisp, 2007:51). In previous years students had a tendency to link in law and policy, without providing a critique so changes were made to the Law and Policy module on the programme to reflect this and to allow students to gain a wider knowledge base around the many different areas of law that impact on social work practice. The law and policy analysis in the portfolio also encourages students to consider the positive and negative aspects of law and policy and the impact it can have on service users, allowing them to make direct links to practice. This in turn allows students to apply and deepen their understanding of legislation in practice (Preston-Shoot et al., 1997:4). The reflective summary is set up around the nine domains of the PCF (TCSW, 2012) allowing students to really reflect on areas of their practice and development, making links to other areas within

55 J. of Practice Teaching \& Learning 12(2), pp.48-66. DOI: 10.1921/5702120201. @ w\&b 2013 
the portfolio and the new frameworks. In relation to practice educators in statutory settings reporting that students do not come prepared enough to undertake complex assessments in their final year, students are now also required to provide an example of an assessment they have undertaken, demonstrating their ability to gather information, analyse and use evidence bases practice and develop an action plan of intervention.

Practice educators are encouraged to evidence other pieces of work in relation to the student's development of their capabilities, not already submitted through the portfolio, but shown through observation and supervision of the student through their practice educator mid-way and final reports. In tandem with introducing the changes to the portfolio requirements and updating academic, teaching and learning material with the new frameworks, the 30 skills development days were introduced. 26 of these days were embedded into the Year 1, year-long module entitled Preparation for Practice, that includes a 10 day observational placement experience and a recorded interview of a service user, lectures and workshops focused on developing the student's 'readiness for practice'. The module is assessed via a portfolio of evidence to get students ready for undertaking this on a larger scale in Years 2 and 3. The remaining 4 skills development days are shared between Years 2 and 3 through whole group lectures around developing an advanced and critical understanding of reflection, building resilience and managing change. The implementation was underpinned with a thorough evaluation incorporating all stakeholders to allow the pilot year to undergo review and revision prior to the start of the next academic year.

\section{Evaluation}

Evidence and feedback was gathered throughout the implementation of the new frameworks from a number of sources. Students and service users were asked to provide feedback in relation to using and making reference to the new frameworks through written assignment tasks and the placement portfolio of evidence at Course Committee meetings. Although final year students found it initially quite daunting to switch from having used the National Occupational Standards (Topps England, 2002) in Year 2 to the new frameworks in Year 3 they reported positively on being able to adapt, finding the portfolio requirements and supporting guidance easy

56 J. of Practice Teaching \& Learning 12(2), pp.48-66. DOI: 10.1921/5702120201. @ w\&b 2013 
to use. Students across Years 2 and 3 were also pleased that the amount of written work required for portfolio assessment had been reduced. Students commented overall that they found the new frameworks easier to understand and map to their academic/reflective writing.

Focus group discussions took place at the end of the six Practice Educator Workshops who were run throughout the academic year and the practice educator and service user Practice Assessment Panels at mid-way and final point of submission of the portfolio. Some of the independent practice educators that work for different HEIs were finding it difficult to work with the both the old and new systems in place, but generally felt that the new frameworks would be easier to digest and work with, with the passing of time. Feedback in relation to the portfolio requirements, guidance and practice educator report was largely positive with some areas being identified as needing more of a focus (that is guidance on completing the assessment task, being able to assess the level of attainment in relation to the capabilities and needing more guidance on using the practice educator reports in a more holistic way). The academic social work team also provided feedback through regular team meeting discussions and staff development days and again reported positively on the changes that had taken place and the guidance and support provided. External examiners at the final assessment board were impressed with the process and layout of the portfolio requirements and the mapping of the new frameworks against assessment tasks. They also highlighted the significant rise in the quality and standard of assessed student work in relation to the use of law and policy, theory to practice and critical analysis, which was linked to an overall increase in higher grades being awarded.

When the majority of Year 2 and Year 3 students had completed their placement experiences the 62 partner agency and independent practice educators who were supervising and assessing students were sent a questionnaire that they completed anonymously at the same time as giving consent for the information to be used as part of this study, yielding a response rate of 48. The questionnaire consisted of 9 questions that asked practice educators if they felt that the new frameworks captured and allowed evidence to be gathered for the wide range of learning experiences needed during a practice placement alongside how easy or not they were to interpret. They were also asked if the portfolio of evidence assignment tasks mapped well against the new frameworks and whether the guidance provided to students and practice educators was sufficient. Lastly they considered their ability to write the practice educator report, their use of the

57 J. of Practice Teaching \& Learning 12(2), pp.48-66. DOI: 10.1921/5702120201. @ w\&b 2013 
direct observation proforma and whether or not they had found the practice educator workshops informative and educational. Space was provided to allow respondents to provide any further qualitative feedback they wished to add. A psychometric Likert scale was used that asked practice educators to rate the questions between 1 and $5(1=$ strongly disagree to $5=$ strongly agree).

\section{Discussion and findings}

In response the first four questions Figure 1: shows that practice educators rated the ability of the new frameworks to allow evidence to be gathered from the placement experience between Agree and Strongly Agree, only one respondent gave a scale rate of 2 . Interestingly although the PCF scored slightly higher in relation to interpreting the domains, the SoPS were rated slightly higher in terms of their use for gathering evidence. Practice educators also provided a number of mixed responses;:

'The frameworks are very repetitive due to their holistic nature'.... 'Difficult to demonstrate depth and level'. 'Felt very unfamiliar I am sure this will ease with time'.... 'The new standards are wide ranging but difficult to write to in terms of the enormity of the number of sub-sections'.

'I found the process really easy to work with'... 'PCF encompasses a wide range of skills, values and academic learning'... 'They do allow for the gathering of information'.....'I found them easy to interpret albeit section 9'..... 'Having the standards mapped against the PCF is helpful'.

.... 'They do give a good level of choice, are easy to read allowing the mapping out of skills and knowledge development'... Yes easy to understand, referring to them during each supervision session and keeping a record of the evidence being gathered by the student allowed them to be digested'.

It is clear that despite some reservations practice educators were getting to grips with using the new frameworks to underpin their supervision and assessment of students.

The responses to the questions around whether or not the portfolio of evidence tasks were mapped well to the new framework, whether the guidance provided was sufficient and ability to write the practice educator

58 J. of Practice Teaching \& Learning 12(2), pp.48-66. DOI: 10.1921/5702120201. @ w\&b 2013 
Figure.1: Professional Capabilities Framework and Standards of Proficiency for social Work: Interpretation of and ability to allow evidence to be gathered for the wide ranging learning experiences needed during and practice placement

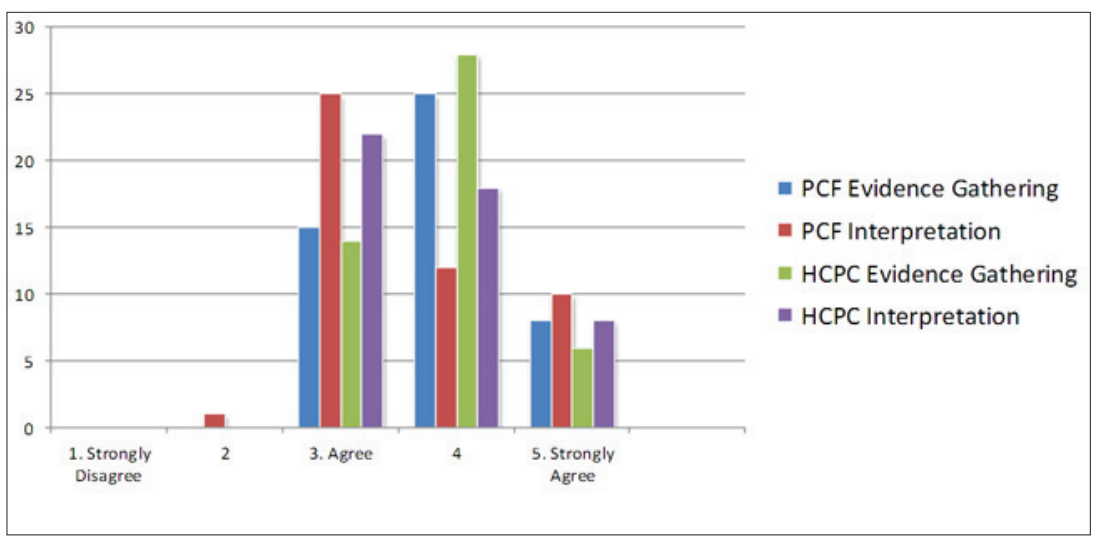

Figure 2: Mapping Portfolio tasks to the Professional Capabilities Framework and Standards of Proficiency for Social Work alongside guidance provided: Writing the Practice Educator Report and use of the Direct Observation Proforma

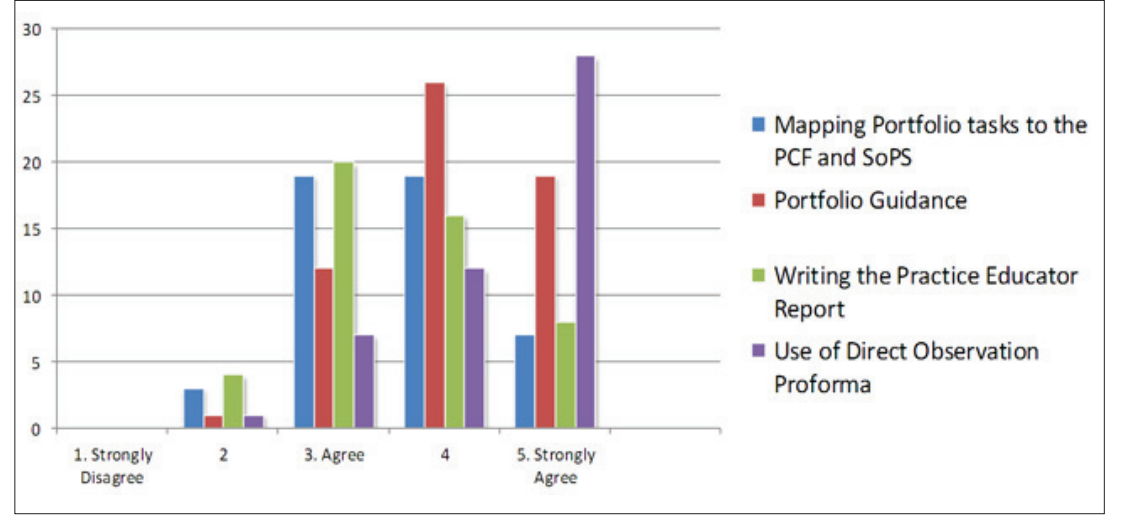

report and use of the direct observation proforma yielded slightly varying results. Figure 2 shows the mapping of the portfolio tasks to the new frameworks fell largely around an 'agree' scale of 3 and 4 with 3 respondents scaling at 2 and 7 at 5 . In terms of the portfolio guidance that was provided, the majority of responses fall between 4 and 5. This suggests that the new and adapted assignment tasks caused some disparity which could be linked 
to their unfamiliarity but the guidance provided to assist in the completion of the tasks was generally useful.

The practice educator report that was set around the nine domains of the PCF (TCSW, 2012) and also asked practice educators to identify future learning needs, was rated between 4 and 5 for the most part, demonstrating the ability of practice educators to gather evidence and to disseminate this through their assessment and evaluation of the student's capabilities. The majority of practice educators strongly agree with the usefulness of the direct observation process and proforma with only one giving a rating of 2 . This is likely to be related to the clear guidance that is provided in relation to the detail required in the proforma that is completed and the process being well embedded into the programme. Practice educators also stated:

'Students have to produce less work for their portfolio, with the large number of SoPs and the PCF it is not always easy for these to be evidenced'... 'The tasks work well but limited word counts appeared difficult at times for students'... 'Concerned how students will manage completing all the work when placements reduce to 70 days'. 'The introduction of critically analysing law and policy and theory to practice in more depth is an excellent addition'.....'The information provided in relation to the portfolio requirements was clear and specific in detailing evidence and competencies required by the student and practice educator'...... 'I do think the guidelines on the assessment task are not clear enough'. 'It was clear what was required for the report but the detail and repetitiveness in the PCF made it difficult'..... 'New to the process struggled a bit with the report I am sure this will be easier second time around?.

The feedback indicates some revision needed around guidance for assignment tasks and a clearer emphasis being placed on practice educators themselves to provide further evidence through their reports that does not appear in the portfolio.

\section{Supporting practice educators}

University Campus Suffolk has always provided some level of support to practice educators, but during the last four years have introduced a series of regular (usually six) practice educator and on-site supervisor workshops that run through the academic year. The workshops are intended to create a supportive teaching and learning environment for the purpose of gaining

60 J. of Practice Teaching \& Learning 12(2), pp.48-66. DOI: 10.1921/5702120201. @ wEb 2013 
and sharing information, that have specific themes linked to the social work practice placement process. Ultimately they aim to provide an open forum for sharing practice experiences and resources. The workshops are delivered by the social work team placement initiative coordinator and encourage delivery from experienced practice educators. To date workshops have included themes around, managing supervision, direct observations, theory to practice, anti-oppressive practice, critical thinking, law and policy, communication and interviewing skills, reflective skills, managing boundaries, supporting students managing disclosures of child sexual abuse and domestic violence, how students learn, motivational interviewing, transactional analysis, assessing and marking the final portfolio, failing and marginalised students, gathering evidence and using holistic assessment and more recently implementing the new frameworks and the practice educator professional standards. The sessions are geared towards allowing practice educators to develop their own knowledge, skill and value base at the same time as introducing some of the teaching and learning on the programme that students are exposed to, to allow a greater integration of classroom based learning and work based learning.

Workshops are followed by practice educators and on-site supervisors being given the opportunity to join a group supervision session and also incorporate regular evaluation and review sessions to ensure the workshops are providing the training and support that practice educators feel they need. Alongside the workshops and group supervision the placement initiative coordinator also provides one to one mentoring and support via telephone or email contact or face-to-face visits when requested. This service has been greatly appreciated by partner agencies and practice educators. The workshops are also supported with an annual Social Work Practice Education Conference that is currently approaching its third year. The conferences have allowed UCS and its partner agencies to keep practice educators up-to-date with the recent reform which has included representation from Skills for Care, the College of Social Work and key speakers and authors from the field of practice education.

As part of the evaluation questionnaire practice educators where asked to rate and comment on their experience of attending the practice education workshops in relation to whether or not they were informative and educational. Figure 3 shows that the majority of practice educators strongly agree that the workshops are informative and educational with only 2 practice educators giving a rate of 3 . General feedback from practice educators included:

61 J. of Practice Teaching \& Learning 12(2), pp.48-66. DOI: 10.1921/5702120201. @ w\&b 2013 
Figure 3: Practice Educator Training Workshop: Are they Informative and Educational?

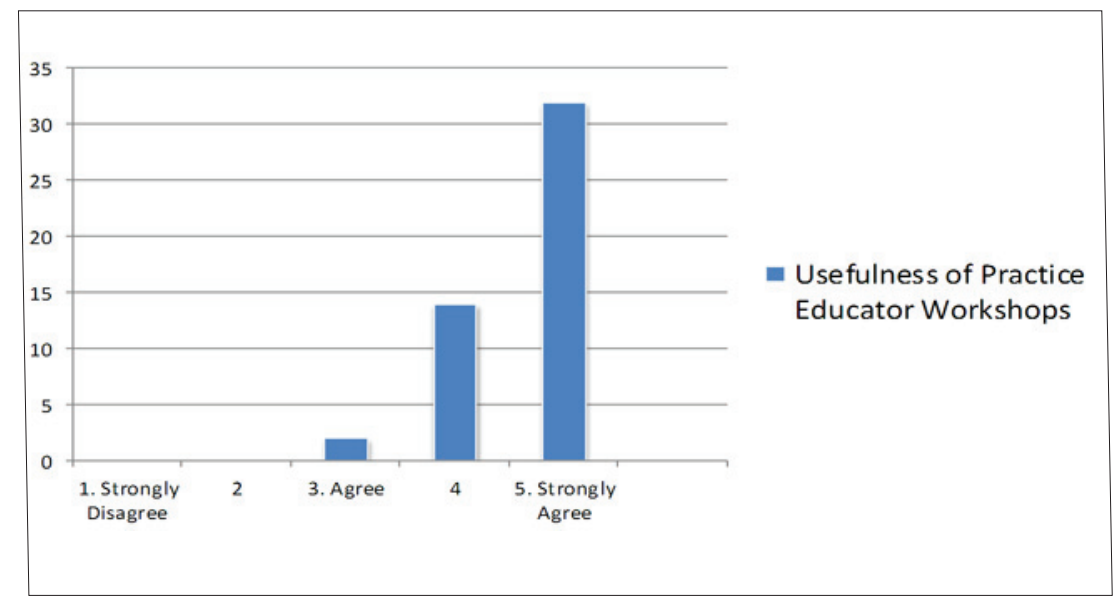

They provide excellent learning but also networking and sharing'. 'Very valuable would be helpful if they could be repeated on different days'. Workshops are superb, stimulating, updating and developing me very well'. Workshops are incredibly worthwhile both in terms of developing practice and meeting up with other practice educators which can feel very isolating at times.

The quotations clearly highlight the importance and relevance of the workshops to practice educators both in terms of providing a teaching and learning space for continued professional development and the opportunity to feel less isolated and able to meet with and share best practice ideas with other practice educators.

\section{Conclusion}

Whilst there is no doubt that the integration and implementation of the new frameworks into the BA (Hons) Social Work programme at UCS has been a journey of complex, active and industrious hard work requiring a tremendous amount of re-organisation, the pilot year has largely been a success, albeit there are some lessons to be learned. The new framework grids that have been used as a means of holistically assessing students have

62 J. of Practice Teaching \& Learning 12(2), pp.48-66. DOI: 10.1921/5702120201. @ w\&bb 2013 
been developed to include level descriptors where both the student and practice educator can work together to assess whether or not the student is 'Confident', 'Effective', 'Satisfactory' or still 'Needs to Develop' key areas of their practice. This has been in line with the model used by the lead partner agency which has integrated this process into the ASYE (Skills for Care, 2012) who through sharing 'best practice' have ensured that our final year students will leave the programme with an up to date report that is streamlined with their continued professional develop during their first year as newly qualified social workers. In line with student feedback, the portfolio requirements have been culled down for first stage placement students to allow enough time to complete the tasks when the placements drop to a 70 day experience. The guidance in the portfolio requirements around key areas of work such as the assessment and intervention task has also been strengthened. To encourage more reflection in the portfolio, students will also be required to attach extracts from their reflective logs to supervision notes at key points during the placement experience.

Practice educator workshops have been organised to allow the sharing of these new developments and will include teaching and learning and further guidance around encouraging practice educators to take more responsibility for including evidence not submitted in the student's portfolio through their written practice educator reports. This will run in tandem with further guidance around the domains of the new frameworks and how they can be evidenced in practice. Equally of importance is the need for all HEIs and partner agencies to remain aware of the pressures facing practice educators under the new regulations and developments in relation to mounting work commitments and demands made on their time undertaking what can be a very isolating role and to acknowledge this through providing regular training, guidance, supervision and support. What is clear from this evaluation is that practice educators really value good quality training and support throughout their supervision and assessment of students at key points during the placement experience. The commitment and full focus on developing close collaborative working relationships with all stakeholders is also of fundamental importance for ensuring the success of the new developments which will need to continue in line with forthcoming revalidation, endorsement and inspection of social work training programmes.

As social work continues to voyage through yet another sea of change that will go beyond the implementation of the new frameworks and registering of practice educators to face the implications of reduced social work bursaries

63 J. of Practice Teaching \& Learning 12(2), pp.48-66. DOI: 10.1921/5702120201. @ w\&b 2013 
and the need to continue to focus on providing high quality placements (Munro, 2011, p.98) alongside the governments new plans for further review of social work training (Association of Directors for Children's Services, 2013) it will ultimately continue to face new challenges. Parker (2013) during a recent conference presentation entitled 'the trouble with practice education' usefully reminds us to remain aware and able to challenge the 'external pressures to conform to consistent standards, based on universal models of practice learning with increased prescription to improve practice quality. College of Social Work experts, academics and practitioners are also set to begin debating the key issues facing practice educators (TCSW, 2013). Whilst UCS has taken on board the requirements of the new reforms and will continue to review and develop on the back of a successful pilot year of implementation and overarching positive feedback, what rings clear is the need for social work academics and professionals to stay tuned in to their 'radical' roots. This will require us to have the dexterity to question and challenge, if we are to maintain our capacity to provide a high quality 'student experience' based on creativity and innovation juxtaposed against a turbulent political and economic climate that will undoubtedly continue to put pressure on all those involved in maintaining the social work profession.

\section{References}

Association for Directors of Children's Services (2013) Workforce Development: Annual Report. Available at: http://www.adcs.org.uk/committees/wd-pc.html. Accessed on: 10/08/2013.

Barnett, R. and Coate K. (2005) Engaging the Curriculum in Higher Education. Maidenhead: SRHE and Open University Press.

CCETSW (1989) Improving Standards in Practice Learning: Regulations and guidance for the approval of agencies and the accreditation and training of practice teachers. Paper 26.3. London: CCETSW

Department of Health (2002) Requirements for Social Work Training. London: DoH Durkin, C. and Shergill, M. (2000) A team approach to practice teaching. Social Work Education, 19, 2, 165-174

Green Lister, P. and Crisp, B. (2013) Critical incident analyses: A practice learning tool for students and practitioners. Practice, 19, 1, 47-60

General Social Care Council. (GSCC) (2005) Post-qualifying Framework for Social Work Education and Training. London: GSCC

64 J. of Practice Teaching \& Learning 12(2), pp.48-66. DOI: 10.1921/5702120201. @ wEb 2013 
Health and Care Professions Council (2012) Standards of Proficiency: Social Workers in England. London: HCPC. Available at: http://www.hpc-uk.org/assets/ documents/10003B08 Standardsofproficiency-SocialworkersinEngland.pdf. Accessed on: 27/08/2013.

Keen, S. Parker, J. Rutter, L. Williams, S. and Brown, K. (2010) Practice education: Where next? Journal of Practice Teaching and Learning. 10, 2, 63-88

Lindsay, J. and Walton, A. (2000). Workforce Planning and the Strategic Development of Practice Teachers in Approve Agencies in the CCETSW England Regulation 1999. London: CCETSW/Kingston University

McNay, M. Clarke, J. and Lovelock, R. (2009) The journey towards professionalism in social work: The development of assessment and practice learning. Journal of Practice Teaching and Learning, 9, 3, 72-91

Munro, E. (2011) The Munro Review of Child Protection: Final Report. A child centred system. Department of Education. London: HMSO.

Novell, J. (2013) Support for Social Work Students Online Debate. . [Online]. Available at: http://www.tcsw.org.uk/professional-development/communitiesof-interest/? . Accessed on: 27/07/2013

O'Hagan, K. (1996) (Revised 2007) Competence in Social Work Practice. London: Jessica Kingsley

Parker, J. (2013) The Trouble with Practice Education. Conference paper, presented June 2013. Ipswich, University Campus Suffolk: Annual Social Work Practice Education Conference.

Preston-Shoot, M. Roberts, G. and Vernon, S. (1997) 'We work in isolation and in ignorance occasionally': On the experiences of practice teachers teaching and assessing social work law. Social Work Education, 16, 4, 4-34

QAA (2000) Social Policy and Administration and Social Work: Subject benchmark statements. Gloucester: Quality Assurance Agency for Higher Education.

Skills for Care (2009) Proposals for a Practice Educator Framework. Available at: http://www.skillsforcare.org.uk/socialwork/practiceeducation. Accessed on 27/07/2013

Skills for Care and The Department for Education (2012) What is the Assessed and Supported Year in Employment? Available at: http://www.skillsforcare. org.uk/socialwork/ ASYElWhatistheASYE/WhatisASYE.aspx. Accessed on 27/07/2013.

The College of Social Work (2012) Student Social Worker Levels Professional Capabilities Framework. Available at: http://www.tcsw.org.uk/uploadedFiles/ TheCollege/CollegeLibrary/Reform_resources/PCF5 FullTableStudentLevels. pdf. Accessed on 28/07/2013.

The College of Social Work (2012) The Practice Educator Standards for Social Work

65 J. of Practice Teaching \& Learning 12(2), pp.48-66. DOI: 10.1921/5702120201. @ w\&b 2013 
(PEPS). Available at: http://www.tcsw.org.uk/uploadedFiles/TheCollege/_ CollegeLibrary/Reform_resources/Practice-EducatorProfessional(edref11).pdf. Accessed on 28/07/2013

The College of Social Work (2013) Practice Education: Online Debate. London: TSCW. Available at: http://www.tcsw.org.uk/professional-development/ communities-of-interest/?terms=debates. Accessed on 24/07/2013.

The Social Work Reform Board (2010) Building a Safe and Confident Future. SWRB. Available at: http://www.education.gov.uk/swrb. Accessed on 28/07/2013

Thompson, N. Osada, M. and Anderson, B. (1994) Practice Teaching in Social Work. (2nd ed.) Birmingham. Pepar Publications.

Topss England (2002) National Occupational Standards for Social Work. Topps UK Partnership.

Walker, J. Crawford, K. and Parker, J. (2008) Practice Education in Social Work: A handbook for practice teachers, assessors and educators. Exeter: Learning Matters.

Williams, S. and Rutter, L. (2010) The Practice Educator's Handbook. Exeter: Learning Matters. 